\title{
Long Lifetime DC-Link Voltage Stabilization Module for Smart Grid Application
}

\author{
Huai Wang*, Henry Chung ${ }^{\dagger}$, Wenchao Liu ${ }^{\dagger}$, Frede Blaabjerg* \\ * Center of Reliable Power Electronics (CORPE), Department of Energy Technology, Aalborg University, Denmark. \\ ${ }^{\dagger}$ Centre for Smart Energy Conversion and Utilization Research (CSCR), City University of Hong Kong, Hong Kong. \\ hwa@et.aau.dk; eesch@cityu.edu.hk; wenchao.liu@cityu.edu.hk; fbl@et.aau.dk
}

\begin{abstract}
Power converters enable efficient and flexible control and conversion of electric energy among different smart grid players (i.e. producers, energy storage systems, and loads). One of the expected features of smart grid is that it will be more reliable compared to conventional grid. However, power converters are one kind of the lifetime limiting components applied in smart grid. One of the major causes is the malfunction of electrolytic capacitors (E-Caps) which are widely used for stabilizing the dc-link voltage in various types of power converters applied in smart grid. A dc-link module is therefore proposed in this paper with a reduced value of dc-link capacitor and a series voltage compensator. It allows the replacement of the popularly used E-Caps with alternatives of longer lifetime, like power film capacitors. The basic concept, implementation and operation principle of the dc-link module are given. The theoretical analysis is verified by simulation and experimental results.
\end{abstract}

\section{INTRODUCTION}

The smart grid is characterized by a two-way flow of energy and information, which creates an automated, widely distributed energy generation and delivery network [1]. Fig. 1 gives a possible scenario of the future power system based on smart grid technologies [2]. Power electronic building blocks (PEBBs) and mechanical building blocks (MEBBs) are the intelligent energy conversion nodes interconnecting the producers, energy storage systems and loads. PEBBs composed of power converters enable efficient and flexible control and conversion of electric energy. However, the reliability issue of PEBBs as discussed in [3] is a challenge in smart grid applications.

PEBBs have various architectures, of which the ones shown in Fig. 2 are dominant for power generation, transmission, and consumption in the smart grid. They are widely applied in lighting application, telecom power supplies, photovoltaic (PV) systems, wind turbine systems and so on. Multiple power converters are interconnected by a dc link. The dclink voltage is supported by a capacitor bank for absorbing instantaneous power difference between the input source and output load, minimizing voltage variation on the dc link, and providing sufficient energy during the hold-up time of the system.

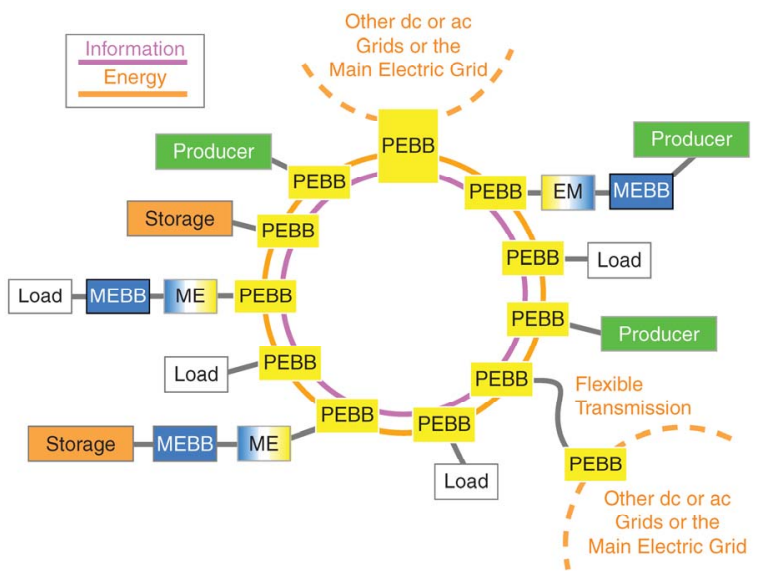

Fig. 1. A possible scenario of the future power system based on smart grid technologies (PEBB- power electronic building block, MEBB- mechanical building block, MEmechanical electrical interface) [2].

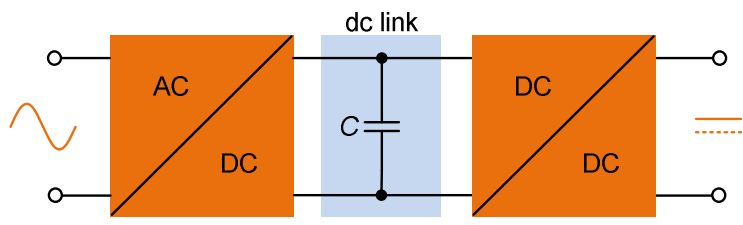

(a) Ac-dc-dc or dc-dc-ac power converters with a dc-link.

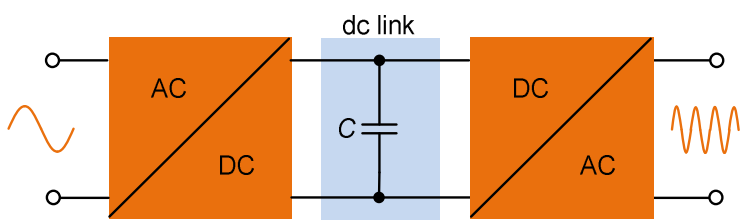

(b) Ac-dc-ac power converters with a dc-link.

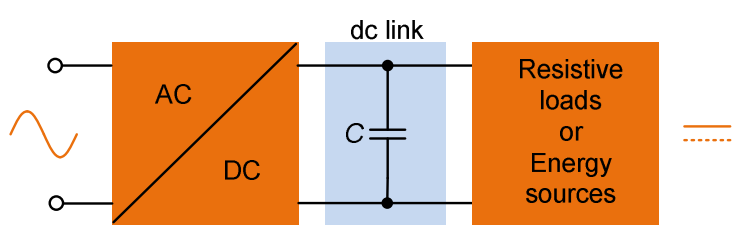

(c) Ac-dc or dc-ac power converters with a dc-link.

Fig. 2. Typical power electronic building blocks used in the smart grid (power flow from left-to-right, right-to-left, or bi-directional). 
Table I. Comparisons between aluminum electrolytic capacitors and power film capacitors.

\begin{tabular}{|c|c|c|}
\hline & $\begin{array}{c}\text { Aluminum } \\
\text { electrolytic } \\
\text { capacitors }\end{array}$ & $\begin{array}{c}\text { Power film } \\
\text { capacitors }\end{array}$ \\
\hline $\begin{array}{c}\text { volumetric } \\
\text { efficiency }\end{array}$ & high & relatively low \\
\hline $\begin{array}{c}\text { voltage } \\
\text { ratings }\end{array}$ & $\begin{array}{c}\text { from low voltage to } \\
700 \mathrm{~V}\end{array}$ & $\begin{array}{c}\text { from low voltage } \\
\text { to } 100 \mathrm{kV}\end{array}$ \\
\hline $\begin{array}{c}\text { capacitance } \\
\text { tolerance }\end{array}$ & typical $\pm 20 \%$ & $\begin{array}{c}\text { typical } \pm 5 \%, \\
\pm 10 \%\end{array}$ \\
\hline $\begin{array}{c}\text { ripple } \\
\text { current }\end{array}$ & typical $20 \mathrm{~mA} / \mu \mathrm{F}$ & typical $1 \mathrm{~A} / \mu \mathrm{F}$ \\
\hline ESR** & high & Low \\
\hline lifetime & $\begin{array}{c}\text { typical } 2,000 \text { to } \\
10,000 \text { hours } *\end{array}$ & $\begin{array}{c}\text { typical } 100,000 \\
\text { hours* }\end{array}$ \\
\hline cost & low & relatively high \\
\hline
\end{tabular}

*Under rated conditions. ** Equivalent series resistance.

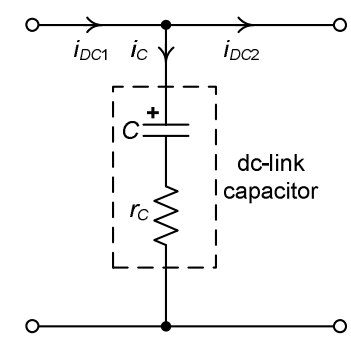

(a) Additional control schmes

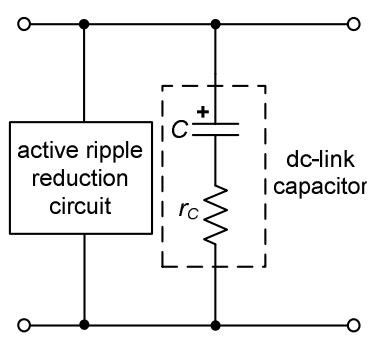

(b) Active ripple reduction circuits
Fig. 3. Prior-art concepts for reducing dc-link capacitors.

Among different types of capacitor, aluminum electrolytic capacitors (E-Caps) are the most popular choice for the dc-link application because of their high volumetric efficiency and low cost, however, suffering from short lifetime. Power film capacitors outperform E-Caps in terms of power loss, selfhealing capability, life expectancy, dc-blocking capability, ripple current capability, reliability, and environmental performance. The challenge is that the volume and cost of power film capacitors are 510 times of those of E-Caps with same voltage rating and capacitance. Table I gives the comparisons between these two types of capacitors.

To lessen the dependency of the dc-link capacitance, there are several prior-art methods for reducing the required energy storage as shown in Fig. 3. One is by adopting control methods to render the current $i_{D C 1}$ to $i_{D C 2}$ as shown in Fig. 3(a) [4]-[9]. The performance of the controllers is highly dependent on the accuracy of the calculations and affected by time delays. Moreover, it is not suitable for power factor corrector (PFC) front-end with constant load power applications. The other concept is to add an active ripple reduction circuit in parallel with dc-link capacitors as shown in Fig. 3(b) [10]-[12]. The common challenge of all these methods is that the components used in the auxiliary circuit are under a high voltage stress, which could be as high as the dc- link voltage. In [13], a third port circuit is introduced for power balancing. It requires that the additional port has a power rating the same as that of the main conversion system.

This paper proposes a module that can reduce the required dc-link capacitance for voltage stabilization. Its operating principle is based on connecting a series voltage compensator between the dc-link capacitor and the load. The energy storage in the dc link is reduced, making it possible to replace the high-value E-Caps with low-value high-performance (e.g., lifetime) capacitors. The voltage compensator is of low voltage and low power rating, as it only produces low voltage and handles reactive power. Its implementation only requires low-voltage switching devices and low-voltage capacitors of long lifetime. The developed module could be integrated into different type of PEBBs that are suitable for smart grid applications. The basic concept, implementation, operation principle, simulation and experimental verifications are presented in the following sections.

\section{CONCEPT OF THE PROPOSED MODULE}

Fig. 4 depicts the basic concept of the module for reducing the dc-link capacitance. The dc-link capacitor is connected to the output of the first power converter. The capacitor voltage $v_{C}$ is composed of dc component $V_{C}$ and ripple voltage $\Delta v_{C}$. The peakto-peak value of $\Delta v_{C}$ is $2\left|\Delta v_{C}\right|$. A voltage source $v_{a b}$ is connected in series between the dc-link capacitor $C$ and output $v_{d}$. It generates a voltage counteracting $\Delta v_{C}$ with its dc component equal to zero (i.e., $v_{a b}=$ $\left.\Delta v_{C}\right)$. Thus, $v_{d}$ has the same dc value as that across $C$, but with a zero ripple voltage in the ideal situation. Such architecture allows a high voltage ripple on $C$, implying that the value of $C$ can be made smaller, but at the expense of increasing the magnitude of $v_{a b}$.

From energy storage perspective, the dc-link module has energy storage in both the dc-link capacitor $C$ and the voltage compensator. Fig. 5 shows the energy storage $E$ and instantaneous power $p$ of the dc-link capacitor. The dc component of energy $E_{1}$ maintains a certain level of dc-link voltage. Only the ac component of $E$ requires the power $p$ for balancing the input and output power of the entire system. Therefore, with the proposed dc-link module, the energy storage elements are divided into two parts: one is stored in the reduced dc-link capacitor and the other one is stored in the voltage compensator. The theoretical minimum energy storage required is $E_{\min }$. In the practical design, the overall energy storage of the dc-link module is reduced to a certain level between $E_{1}$ and $E_{\text {min }}$, for example $E_{2}$ as illustrated in Fig. 5. 


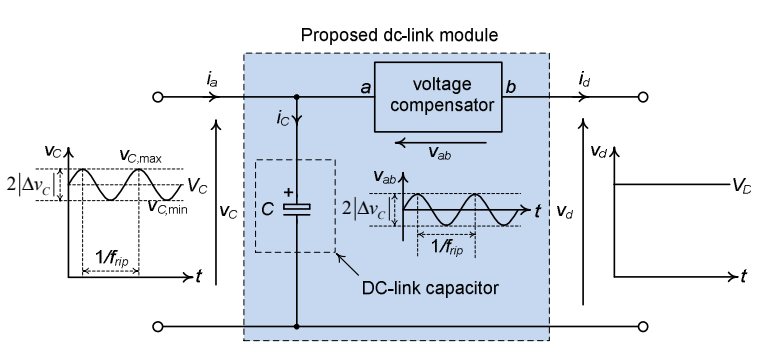

Fig. 4. Basic concept of the proposed dc-link module.

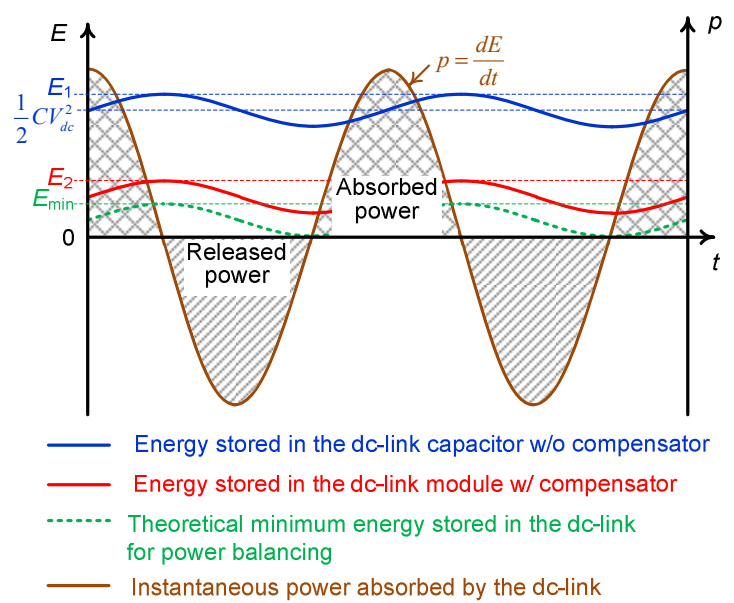

Fig. 5. Energy stored and instantaneous power handled by the dc-link capacitor bank.

\section{IMPLEMENTATION OF THE MODULE}

Fig. 6 shows one kind of the implementation of $v_{a b}$ and its corresponding control method. $v_{a b}$ is generated by a dc-ac converter consisting of a fullbridge (FB) and an output filter formed by the inductor $L_{f}$ and capacitor $C_{f}$. Its dc side is connected to an energy storage device such as a capacitor. The gate signals for the switches $S_{1}-S_{4}$ in the FB are generated by a PWM modulator. It is noted that a half-bridge circuit can also be used if the current $i_{d}$ is unidirectional. $v_{a}$ is regulated at the reference $V_{a, r e f}$ by a feedback loop. The difference between $V_{a, \text { ref }}$ and $v_{a}$ is averaged by a low-pass filter and processed by a PI controller to give an offset voltage $v_{o s}$. $v_{c o n}$ is derived by combining the scaled-down dc link voltage $\alpha v_{C}$ with $v_{o s}$.

The design of the dc-link capacitance value $C$ in the proposed dc-link module is a compromise among the allowable voltage level of $v_{a}$, and the stress on the capacitor $C_{a}$ and the MOSFETs $S_{1}-S_{4}$. A smaller value of $C$ requires higher voltage ratings of $C_{a}$ and $S_{1}-S_{4}$. The capacitor $C_{a}$ withstands a low voltage stress. There are several choices in practical implementation. One choice is to use low voltage ECaps with high ripple current and long lifetime. Unlike the ones with high voltage ratings, they are available and cost-effective. Another choice is to use ceramic capacitor tank or low-voltage film capacitors. The detailed selection of these two capacitors is discussed in [14].

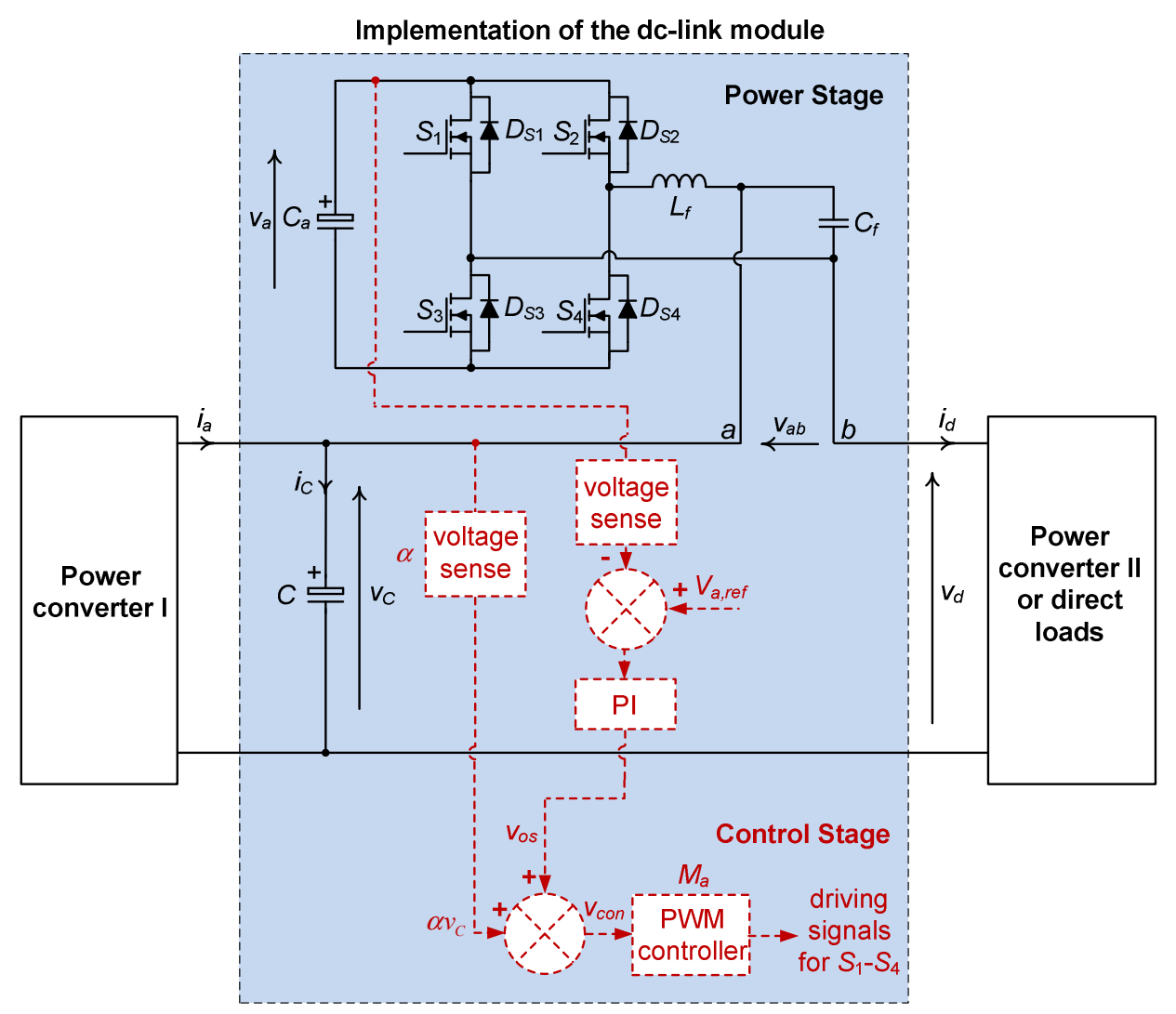

Fig. 6. One kind of implementation of the proposed dc-link module. 


\section{OPERATION PRINCIPLE OF THE VOLTAGE COMPENSATOR}

Figs. 7(a) and (b) present the operation modes of the voltage compensator. When $S_{2}$ and $S_{3}$ are on, the capacitor $C_{a}$ is charged by the load current $i_{d}$ and when $S_{1}$ and $S_{4}$ are on, the capacitor $C_{a}$ is discharged. Fig. 7(c) shows the waveforms of the dc-link capacitor voltage $v_{C}$, modulating signal $v_{c o n}$, carrier signal $v_{t r i}$, and the voltage across $C_{a}, v_{a}$. It should be noted that the feedback signal $\alpha v_{C}$ may contain multiple frequency components as it is obtained by scaling down $v_{C}$. $t_{0}$ and $t_{1}$ in Fig. 7(c) are defined as the two time instants when $\Delta v_{C}$ is across zero within one period. During $t_{0}-t_{1}$, the capacitor $C_{a}$ is being charged by the load current and its voltage increases from minimum to maximum. During $t_{1}-t_{2}$, the capacitor $C_{a}$ is being discharged by the load current from maximum to minimum. Based on Fig. 7 and the SPWM principle discussed in [15], the output of the voltage compensator $v_{a b}$ is in phase with the modulating signal $v_{c o n}$, thus, in phase with voltage ripple across the dc-link capacitor. The detailed derivations of the operation of the proposed dc-link module are presented in [14]. It can be derived that the voltage compensator processes only reactive power except for a special case when the ac components of $i_{a}$ and $i_{d}$ are of same frequency and in phase. For the special case concerned, the dc-link capacitance can be reduced by the synchronization control of the two phases as applied in [7].

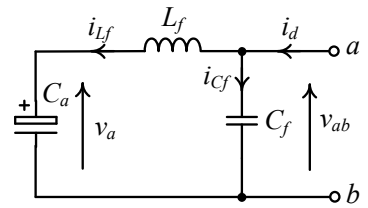

(a)

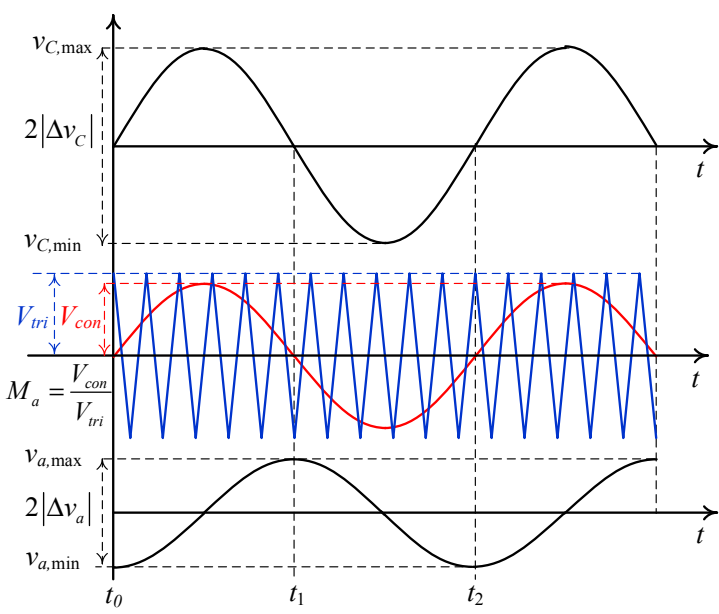

(c)

Fig. 7. Operation modes of the voltage compensator: (a) operation mode when $S_{2}$ and $S_{3}$ are on, (b) operation mode when $S_{1}$ and $S_{4}$ are on and (c) SPWM and the voltage across $C_{a}$.

\section{SIMULATIONS ON THREE PEBBS}

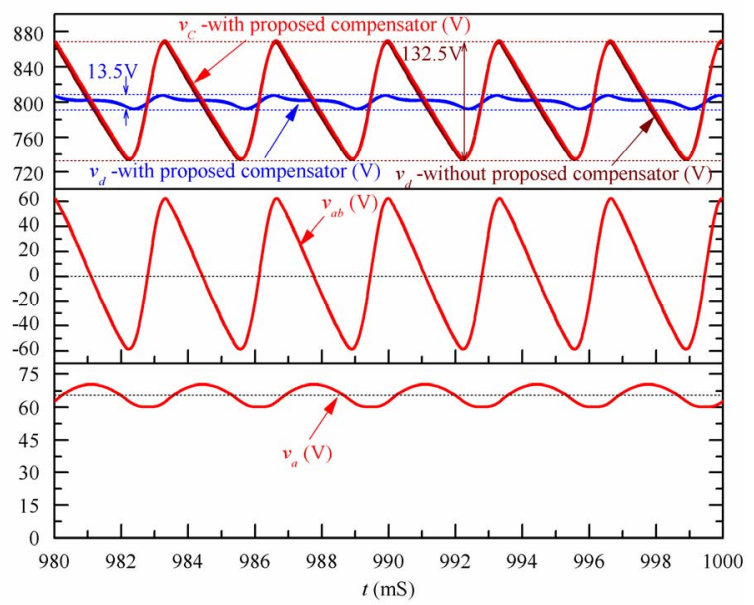

(a) Three-phase uncontrolled diode bridge rectifier with $800 \mathrm{~V}$ dc-link voltage and direct resistive load $\left(P_{o}=2\right.$ $\left.\mathrm{kW}, C: 900 \mathrm{~V} / 40 \mu \mathrm{F}, C_{a}: 100 \mathrm{~V} / 220 \mu \mathrm{F}\right)$.

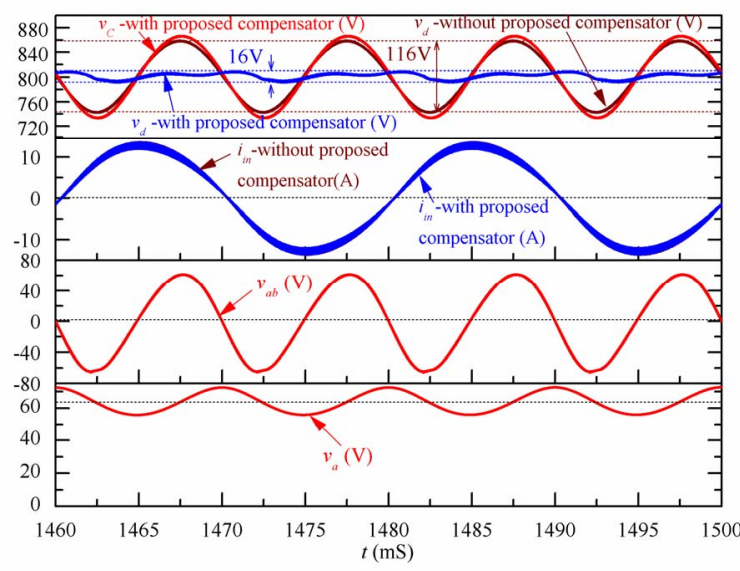

(b) Single phase full-bridge PWM rectifier with $800 \mathrm{~V}$ dc-link voltage and direct resistive load $\left(P_{o}=2 \mathrm{~kW}\right.$, $\left.C: 900 \mathrm{~V} / 50 \mu \mathrm{F}, C_{a}: 100 \mathrm{~V} / 470 \mu \mathrm{F}\right)$.

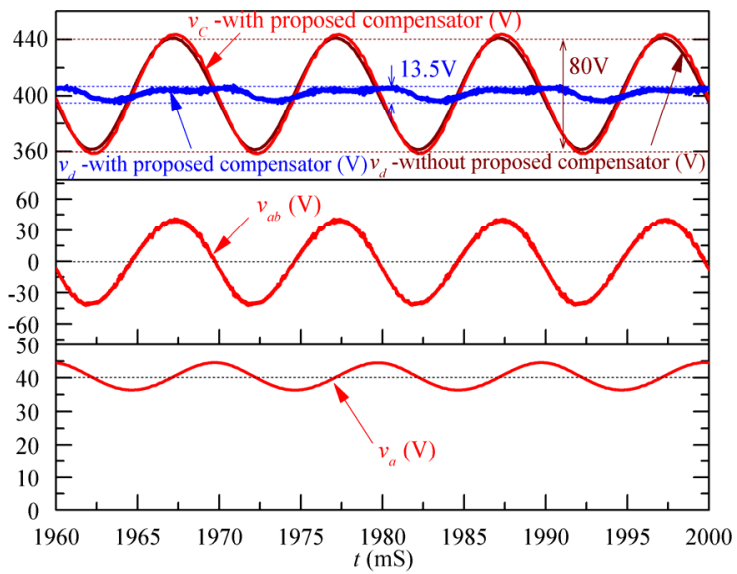

(c) Power factor corrector with $400 \mathrm{~V}$ dc-link voltage and single phase full-bridge dc-dc converter switching load $\left(P_{o}=1 \mathrm{~kW}, C: 450 \mathrm{~V} / 100 \mu \mathrm{F}, C_{a}: 50\right.$ $\mathrm{V} / 1000 \mu \mathrm{F})$.

Fig. 8. Simulation results of three different PEBBs. 
Fig. 8 shows the simulation results on three different PEBBs to verify the feasibility of the proposed dclink module for dc-link voltage stabilization with reduced dc-link capacitance and long lifetime power film capacitors.

\section{EXPERIMENTAL VERIFICATIONS}

For illustration, an experimental study case has been investigated for the PEBB shown in Fig. 2(a). A test bed is built and constructed by connecting a $3 \mathrm{~kW}$ PFC (i.e. power converter I) to a $600 \mathrm{~W}$ phase-shifted full-bridge dc-dc converter (i.e. power converter II). The PFC is supplied by an ac power source with voltage of $220 \mathrm{~V}$ and frequency of $50 \mathrm{~Hz}$. The output of the dc-dc converter is connected to an electronic load and its output voltage is $12 \mathrm{~V}$.

With conventional solution, the dc-link capacitor bank $C$ is implemented by connecting two $330 \mu \mathrm{F}$, $450 \mathrm{~V}$ E-Caps in parallel. According to the manufacturer's datasheet, the lifetime of the capacitors is 3,000 hours at $105^{\circ} \mathrm{C}(12,000$ hours estimated at $85^{\circ} \mathrm{C}$ under rated ripple current and rated voltage stress). The measured dc-link voltage ripple is $10.8 \mathrm{~V}$ and the setting time from $10 \%$ load to full load transition is $100 \mathrm{~ms}$. After a line dropout (i.e. the input $220 \mathrm{~V} / 50 \mathrm{~Hz}$ ac source is turned off), the energy stored in the dc-link capacitor bank solely delivers power to the load. The measured hold-up time is $24.6 \mathrm{~ms}$.

With the proposed dc-link module, a $120 \mu \mathrm{F}(82 \%$ capacitance reduction) film capacitor with the lifetime of 100,000 hours at $85^{\circ} \mathrm{C}$ under rated voltage stress is used to replace the capacitor bank. A 1000 $\mu \mathrm{F} / 63 \mathrm{~V}$ low-voltage E-Cap with the lifetime of 8,000 hours at $125^{\circ} \mathrm{C}(128,000$ hours estimated at $85^{\circ} \mathrm{C}$ under rated ripple current and rated voltage stress, which is comparable with the lifetime of the film capacitor) is used for the voltage compensator, i.e. $C_{a}$. The voltage across $C_{a}$ is designed to be $50 \mathrm{~V}$. Fig. 9(a) shows the steady-state waveforms of the capacitor ripple voltage $\Delta v_{C}$ and module output ripple voltage $\Delta v_{d}$, when the output is at full load. Their peak-to-peak ripple voltages are $49.1 \mathrm{~V}$ and $3.9 \mathrm{~V}$, respectively. Fig. 9(b) shows the transient waveforms of $v_{d}, v_{C}$, module output voltage $v_{a b}$ and dc-dc converter output current $i_{\text {out }}$, when the output is suddenly changed from $10 \%$ load to full load. $v_{d}$ is momentarily reduced by $45.5 \mathrm{~V}$ and its settling time is $100 \mathrm{~ms}$. For the applications with hold-up time requirement, the dc-link capacitance is increased from $120 \mu \mathrm{F}$ to $450 \mu \mathrm{F}$, which is $32 \%$ capacitance reduction and $28 \%$ overall energy storage reduction compared to the E-Caps solution. The hold-up time is measured with $24.5 \mathrm{~ms}$ as shown in Fig. 9(c), which is similar as that of the E-Caps solution.

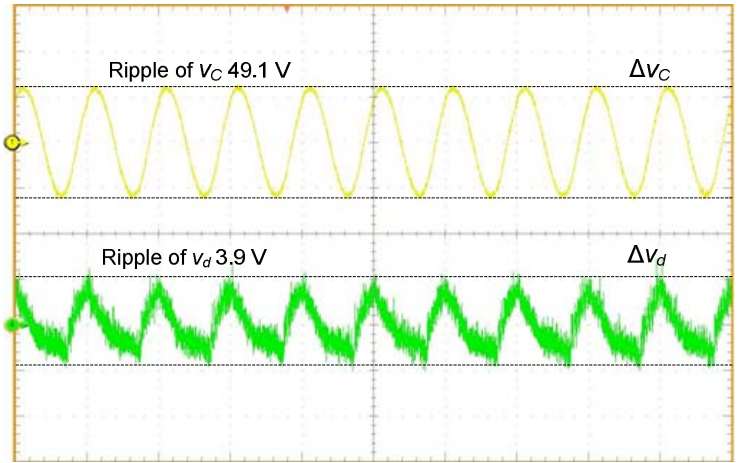

(a) Steady-state waveforms of $v_{C}$ and $v_{d}$ under the fullload condition $\left(\Delta v_{C}: 20 \mathrm{~V} / \mathrm{div}, \Delta v_{d}: 2 \mathrm{~V} / \mathrm{div}\right.$, Timebase: $10 \mathrm{~ms} / \mathrm{div})$.

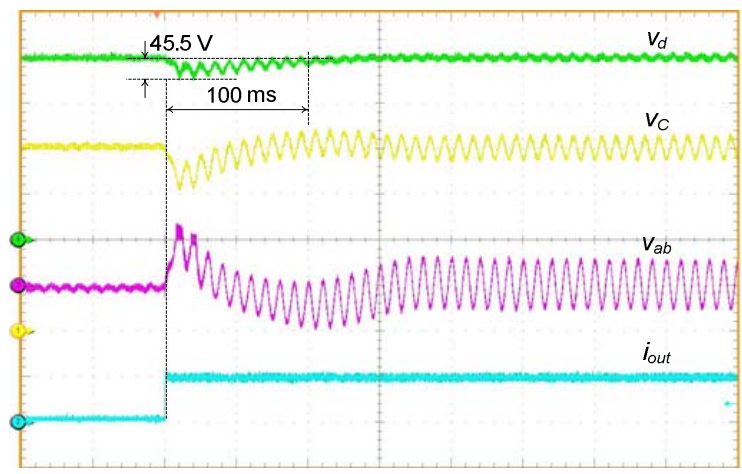

(b) Transient waveforms when the output is changed from $10 \%$ load to full load $\left(v_{d}: 100 \mathrm{~V} / \mathrm{div}, v_{C}: 100\right.$ $\mathrm{V} / \mathrm{div}, v_{a b}: 40 \mathrm{~V} / \mathrm{div}, i_{\text {out }}: 50 \mathrm{~A} / \mathrm{div}$, Timebase: 50 $\mathrm{ms} / \mathrm{div})$.

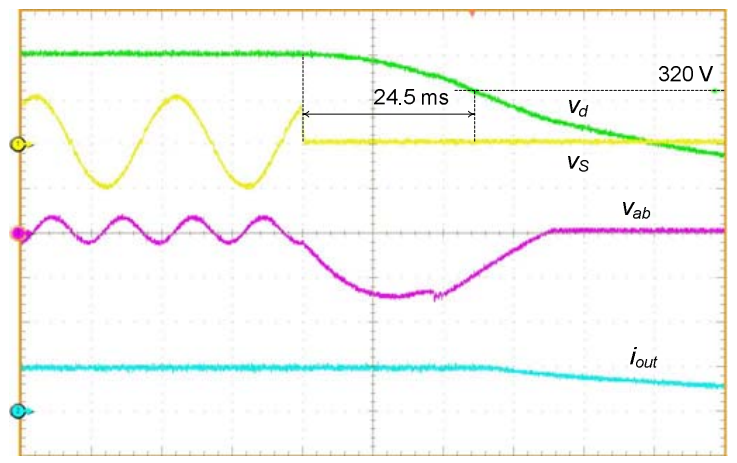

(c) Transient waveforms after a sudden supply outage under the full-load condition $\left(v_{d}: 100 \mathrm{~V} / \mathrm{div}, v_{S}: 300\right.$ $\mathrm{V} / \mathrm{div}, v_{a b}: 20 \mathrm{~V} / \mathrm{div}, i_{\text {out }}: 50 \mathrm{~A} / \mathrm{div}$, Timebase: 10 $\mathrm{ms} / \mathrm{div}$ )

Fig. 9. Experimental waveforms with the proposed dclink module applied in the ac-dc-dc PEBB prototype.

The experimental results reveal that the proposed dclink module can reduce the required capacitance value for the dc-link capacitor without sacrificing the transient and steady-state responses of the power converters. The resulting effect will extend the life expectancy of the entire PEBB from the perspective of reducing the chance of failure due to ageing of the dc link capacitor bank. The proposed method has an additional distinct advantage for high-voltage 
applications in the smart grid, due to the fact that the voltage rating of power film capacitors is usually higher than that of E-Caps. With the proposed module, the dc-link capacitance can be reduced and a fewer number of high-voltage power film capacitors are used to replace the E-Caps which are connected in series to withstand the high voltage.

\section{CONCLUSIONS}

An active dc-link module with a series voltage compensator is proposed for dc-link voltage stabilization of PEBBs which are widely used in the smart grid. The overall energy storage and dc-link capacitance requirement is reduced compared to the conventional E-Caps solution, allowing a costeffective replacement of the short lifetime E-Caps by long lifetime high performance power film capacitors. The implementation of the voltage compensator requires low-voltage devices, because it handles ripple voltage on the dc-link and reactive power only. Simulation and experimental results are in well agreement with the theoretical analysis.

As a critical component, the developed module could be integrated into different type of power converters suitable for smart grid applications. It enables new opportunity to enhance reliability of the smart grid from the component level.

\section{REFERENCES}

[1] F. Bouhafs, M. Mackay, and M. Merabti, "Links to the future: communication requirements and challenges in the smart grid," IEEE Power and Energy Magazine, vol. 10, no. 1, pp.24-32, Jan. /Feb. 2012.

[2] M. Liserre, T. Sauter, and J. Hung, "Future energy systems: integrating renewable energy sources into the smart power grid through industrial electronics," IEEE Industrial Electronics Magazine, vol. 4, no. 1, pp. 18-37, Mar. 2010.

[3] H. Wang, K. Ma, and F. Blaabjerg, "Design for reliability of power electronic systems," Invited keynote paper for IEEE Industrial Electronics Society Annual Conference, Montreal, Canada Oct. 2012.

[4] P. W. Hammond, "Control method and apparatus to reduce current through dc capacitor linking two static converters," US Patent 6,762,947, 2004.

[5] G. Kalman and C. Huggett, "Ac-to-ac power converter without a dc link capacitor," US Patent 6,839,249, 2005.

[6] B. Gu and K. Nam, "A dc-link capacitor minimization method through direct capacitor current control," IEEE Transactions on
Industry Applications, vol. 42, no. 2, pp. 573581, Mar./Apr., 2006.

[7] I. S. Freitas, C. B. Jacobina, and E. C. Santos, "Single-phase to single-phase full-bridge converter operating with reduced ac power in the dc-link capacitor," IEEE Transactions on Power Electronics, vol. 25, no. 2, pp. 272-279, Feb., 2010.

[8] T. Okuda, T. Urakabe, and Y. Kuramoto, "Motor driving apparatus," US Patent 7,310,475, Dec. 18, 2007.

[9] H. Song, D. Oh, K. Nam, and S. Kim, "Method for controlling voltage of dc-link for electric vehicle," US Patent 7,528,566, May 5, 2009.

[10] S. Li, B. Ozpineci, and L. M. Tolbert, "Evaluation of a current source active power filter to reduce the dc bus capacitor in a hybrid electric vehicle traction drive," in Proc. of IEEE Applied Power Electronics Conference, 2009, pp. 1185-1190.

[11] H. Yoo and S. K. Sul, "A new circuit design and control to reduce input harmonic current for a three-phase AC machine drive system having a very small dc-link capacitor," in Proc. of IEEE Applied Power Electronics Conference, 2010, pp. 611-618.

[12] R. X. Wang, F. Wang, D. Boroyevich, R. Burgos, R. X. Lai, P. Q. Ning, and K. Rajashekara, "A high power density singlephase PWM rectifier with active ripple energy storage," IEEE Trans. Power Electron., vol. 26, no. 5, pp. 1430-1443, May 2011.

[13] P. Krein, R. Balog, and M. Mirjafari, "Minimum energy and capacitance requirements for single-phase inverters and rectifiers using a ripple port," IEEE Trans. Power Electron., vol. 27, no. 11, pp. 46904698, Nov. 2012.

[14] H. Wang, H. S. H. Chung, and W. Liu, "Use of a series voltage compensator for reduction of the dc-link capacitance in a capacitor-supported system (Submitted to IEEE Transactions on Power Electronics).

[15] N. Mohan, T. M. Undeland, and W. P. Robbins, Power electronics, converters, applications, and design, John Wiley \& Sons Press, 2003, ch8. 